\title{
A randomized comparative trial of safety and efficacy of topical vitamin $A$ and carboxymethylcellulose $1 \%$ on symptoms of dry eye disease after cataract surgery
}

\author{
Saurabh Nigam', Shalini Gupta', Poonam Gupta ${ }^{3}$ \\ 'Department of Ophthalmology, Sadguru Netra Chikitsalya, Chitrakoot, India \\ ${ }^{2}$ Department of Ophthalmology, Baba Saheb Ambedkar Hospital and Medical College, Rohini, India* \\ ${ }^{3}$ Department of Ophthalmology, Bhagwati Hospital, Rohini, India \\ *Institution where the study was performed
}

\begin{abstract}
BACKGROUND: The objective of the study was to evaluate the efficacy and safety of topical vitamin A and carboxymethylcellulose (CMC) $1 \%$ in reducing dry eye symptoms after phacoemulsification cataract surgery.

MATERIAL AND METHODS: A prospective interventional randomized comparative open-labeled study was conducted during which all patients undergoing phacoemulsification for age-related cataracts were included. The 270 patients were equally and randomly divided into the three groups A-C of 90 patients each: Group A - patients treated with CMC 1\%, Group B - patients treated with retinyl palmitate (vitamin A), and Group C - patients with only conventional post-operative topical therapy. The outcome measures were changes in visual acuity, Schirmer test results, tear break-up time, mean goblet cell density (MGCD), and ocular symptoms in terms of Ocular Surface Disease Index (OSDI) at follow-up of 1 month. Any side effects due to interventions were also noted in the follow-up period.

RESULTS: On day $30^{\text {th }}$, the final Schirmer test results (mean \pm SD) were significantly higher in Group B than in Group $\mathrm{A}$, and controls $(12.3 \pm 2.23$ vs. $11.2 \pm 3.11$ vs. $9.25 \pm 2.51 ; \mathrm{p}<.0001)$; the final tear film break-up time was significantly longer in Group B than in Group A and controls (12.86 \pm 2.56 vs. $11.16 \pm 2.67$ vs. $9.67 \pm 2.86$; $\mathrm{p}<.0001$ ); there was an increase in the MGCD (mean \pm SD) in all the three groups with the values being significantly higher in Group B vs. Group A vs. controls $(309.07 \pm 20.26$ vs. $295.18 \pm 22.96$ vs. $277.84 \pm 20.86$, $\mathrm{p}<.0001)$ and the final OSDI scores were significantly lower in Group B than in Group A, and controls $(33.42 \pm 1.79$ vs. $34.46 \pm 2.29$ vs. $39.83 \pm 1.72, \mathrm{p}<.0001)$. Adverse effects were as follows: foreign body sensation, red-eye, and eye swelling, which were similar among the study groups ( $\mathrm{p}>0.05)$.

CONCLUSION: We conclude that the use of topical vitamin A on the corneal surface post-cataract surgery reduces the symptoms of dry eyes much faster than $1 \% \mathrm{CMC}$ or conventional treatment. However, all three interventions carried a similar profile of side effects.
\end{abstract}

KEY WORDS: dry eye disease; cataract surgery; carboxymethylcellulose; vitamin A

Ophthalmol J 2021; Vol. 6, 89-100 


\section{INTRODUCTION}

Dry eye disease (DED) is a common disease with a prevalence of $9.5 \%$ to $90 \%$ globally [1] and $18.4 \%$ to $54.3 \%$ in India [2-4]. In India, there has been a surge in DED prevalence from $29.25 \%$ in 2010 to $46.71 \%$ in 2016 and $54.3 \%$ in the current period [1-4].

An association has been observed between DED and routine cataract surgeries (phacoemulsification) [5]. The number of cataract surgeries has increased tremendously in India in the past two decades [6] and may explain the increase in DED prevalence in India.

Phacoemulsification is increasingly applied in the management of cataract patients because of its earlier refractive stabilization, reduced induced astigmatism, and milder postoperative inflammation, all resulting in faster visual rehabilitation [7]. Many patients are dissatisfied after cataract surgery because of tear film dysfunction, poor near vision, and reduced contrast sensitivity despite excellent gains in postoperative vision $[7,8]$. This hampers the quality of life of the patients even after successful cataract surgery [8].

The underlying mechanism of dry eye after phacoemulsification has been ascribed to the transection of the corneal nerves, damage to the corneal epithelial cells, exposure to microscopic light, vigorous intraoperative irrigation of the tear film, the elevation of inflammatory factors in the tear film due to ocular surface irritation, use of topical anesthesia intraoperatively, and topical eye drops administered postoperatively and its preservatives [9]. Vigorous irrigation of the tear film and manipulation of the ocular surface intraoperatively reduces the goblet cell density and results in shortened tear film breakup time (TBUT) postoperatively [10-12].

Topical corticosteroids and non-steroidal anti-inflammatory drugs are used to decrease inflammation and infection in the postoperative period but have limited effectiveness in preventing dry eyes [13-15].

The use of $1 \%$ carboxymethylcellulose sodium (CMC) has been effective in reducing dry eye symptoms and improving TBUT [16-19]. Carboxymethylcellulose is a polymer made of glucopyranose subunits with a negative charge and properties of microviscosity, allowing it to be retained on the cornea for a longer duration and reducing DED post-surgery [16].

Another researched agent is topical vitamin A. Vitamin A is essential for maintaining the health of epithelial cells throughout the body, affecting cellular regulation and differentiation. Vitamin A deficiency adversely affects epithelial cells in the eyelid, conjunctiva, and cornea. Hence, an absence of vitamin A causes the loss of goblet cells and leads to increased epidermal keratinization and squamous metaplasia of the mucous membranes, generally including the cornea and conjunctiva [20].

To our knowledge, there have been no comparative trials of the two therapies in terms of reduction of the occurrence of DED and improvement in the ocular surface. Therefore, in our study, we have compared the efficacy and therapeutic role of ophthalmic vitamin A palmitate gel (Iflomax; vitamin A palmitate 1000 IU and carbomer homopolymer $3.5 \mathrm{mg}$, Ajanta pharmaceuticals, India) with CMC $1 \%$ in treating dry eye signs and symptoms in patients undergoing phacoemulsification surgery using serial clinical examinations, dry eye test, subjective questionnaire, and conjunctival impression cytology.

\section{MATERIAL AND METHODS}

An interventional randomized comparative open-labeled study was conducted in the ophthalmology department, Baba Saheb Ambedkar Hospital and Medical College, New Delhi (India). The study was performed from August to November 2016, during which all patients undergoing phacoemulsification for age-related cataracts were included. Any patients with allergies (or/and using antihistamines), systemic disease (hypothyroidism, rheumatoid arthritis), Stevens-Johnson syndrome, ocular pemphigoid, glaucoma or ocular hypertension (or/and taking antiglaucoma medications), history of chemical or thermal burns of the cornea, eyelid or lacrimal disease, or any ophthalmic surgery within three months before enrollment and contact lens wearer were excluded from the study. The study was approved by the institutional ethical committee (BSAMCH/DNB/2014/4361, dated 10.11.2014).

All patients had signed informed consent for treatment. The sample size calculation was based on the study by Yao et al. [16]. They observed that the efficacy of $1 \%$ CMC sodium for treating dry eye after phacoemulsification in terms of TBUT was significantly higher in the treatment group than the control group on day $30^{\text {th }}(9.0 \pm 5.9$ vs. $6.7 \pm 4.8 \mathrm{~s}$; $\mathrm{p}=0.0258)$. Vitamin $\mathrm{A}$ is assumed as superior to the $1 \% \mathrm{CMC}$ treatment group with a difference of 
$30 \%$. Taking these values as a reference, the minimum required sample size with $80 \%$ power of the study and 5\% significance level is 86 patients in each study group. Taking lost to follow up as 5\%, total sample size accepted stands 270 (90 patients per three groups).

The eligible eyes were randomly allocated by computerized randomization into one of the three groups A-C. For randomization, we prepared fifteen sealed opaque envelopes assigning $\mathrm{A}, \mathrm{B}$, and $\mathrm{C}$ in 5 envelopes each, where A represented CMC $1 \%+$ conventional postoperative topical therapy, $\mathrm{B}$ represented retinyl palmitate (vitamin A) + conventional postoperative topical therapy, and $\mathrm{C}$ represented only conventional postoperative topical therapy. Once a patient provided consent to enter a trial, we opened an envelope, and the patient was then offered the allocated group. After completing 15 patients (5 patients in each group), another section of 15 envelopes was prepared for patient allocation. For the intervention, no allocation concealment was done for the patients or the investigating doctor.

Patients in Group A ( $\mathrm{n}=90)$ were treated four times daily with CMC $1 \%$ and conventional postoperative topical therapy for one month. Carboxymethylcellulose sodium 1\% (Sun Pharmaceuticals Industries Ltd.) branded as Richgel Tears (Eye) $(10 \mathrm{~mL})$ was used, which was stored at room temperature (10-30 ${ }^{\circ}$ Celsius).

Patients in Group B $(n=90)$ were treated four times daily with retinyl palmitate (vitamin A) and conventional postoperative topical therapy for one month. Retinyl palmitate gel (Iflomax, Ajanta pharmaceuticals, India) was used. Each gram included vitamin A palmitate 1000 IU and carbomer homopolymer $3.5 \mathrm{mg}$, which was stored below $25^{\circ} \mathrm{C}$ without freezing.

Patients in Group C $(\mathrm{n}=90)$ were treated neither with CMC $1 \%$ or vitamin A but only with conventional postoperative topical therapy for one month.

The conventional post-operative topical therapy included the use of antibiotic steroid combination (Moxi-P, which contained moxifloxacin $5 \%$ and prednisolone acetate $1 \%$ with a 4-3-2-1 regime: 4 times/daily for one week then three times/day for $2^{\text {nd }}$ week, then twice daily for $3^{\text {rd }}$ week and last once daily for the $4^{\text {th }}$ week), and topical mydriatic (homatropine hydrobromide eye drops $2 \%$, stored below $25^{\circ} \mathrm{C}$ ) twice daily for one month. We maintained a gap of 5 minutes among each of the drops.

\section{Surgery}

Phacoemulsification was performed by a single and the same surgeon using the Infiniti Vision System (Alcon Laboratories), and every time same Ultrasound and fluidic settings were used. Patients were treated under local anesthesia: peribulbar, lidocaine HCL $2 \%$ with hyaluronidase, and bupivacaine.

In phacoemulsification, a 3.2-mm self-sealing scleral incision was made. A VISCOMET ${ }^{\oplus}$ was used to reform and stabilize the surgical planes and protect the corneal endothelium. A 5.5- to 6.0-mm continuous curvilinear capsulorhexis was performed with a 26-gauge needle and the use of trypan blue. A direct chop in the bag phacoemulsification technique was used. The microtip $0.9-\mathrm{mm}$ angled aspiration bypass system phaco tip $\left(45^{\circ}\right)$ was used with a standard setting (torsional mode was fixed $100 \%$ in amplitude). The vacuum limit was $400 \mathrm{~mm} \mathrm{Hg}$; the aspiration flow rate was $38-40 \mathrm{~mL} / \mathrm{min}$, zero dynamic rise, and $100 \mathrm{~cm}$ bottle height. A foldable intraocular lens was inserted with the injector through the main incision wound into the capsular bag, followed by aspiration of VISCOMET and hydration of the incision. No sutures were placed on the clear corneal wound on any patients. Patients were instructed to wash their faces as usual after one week postoperatively and to avoid pressing on the operated eye(s) for one month postoperatively.

\section{Clinical assessment}

One ophthalmologist performed pre- and postoperative assessments. The surgical notes were made accessible to the evaluating ophthalmologist. No concealment of the treatment was done.

Pre-operative assessments included corrected distance visual acuity (CDVA) using Snellen charts, intraocular pressure, and fundoscopic evaluation after pupil dilatation.

The postoperative assessment included uncorrected and best-corrected distance visual acuity (UCVA and BCVA) using Snellen charts.

Besides this, for assessment and comparison of the dry eye, Schirmer tear test 1 (without anesthesia), TBUT, dry eye symptom score in terms of Ocular Surface Disease Index (OSDI), and conjunctival impression cytology for mean goblet cell density (MGCD) were done preoperatively one week and postoperatively at seven and 30 days. The tests were carried out in the same room by the same single examiner, with similar temperature and 
humidity conditions for all patients. During the examination, the room temperature was maintained at $25-26.5^{\circ} \mathrm{C}$, with $60-65 \%$ humidity.

For the TBUT, the patient was seated at the slit lamp. After instilling a drop of $2 \%$ fluorescein into the right eye, the patient was asked to blink a few times before examination. The break-up time of $\leq 10$ seconds was considered positive, indicative of dry eye. Greater than 10 seconds was deemed to be negative [14].

Schirmer's test was done using $5 \times 35 \mathrm{~mm}$ sterile strips of Whatman No. 41 filter paper. Measurements of $\leq 10 \mathrm{~mm}$ were considered to be positive, and $>10 \mathrm{~mm}$ were considered as negative [14].

An OSDI questionnaire was administered to all participants to assess the symptoms of dry eye. The OSDI scale was included for subjective evaluation to have a better subjective picture of the symptoms in relation to their effect on the quality of life. A single examiner administered the questionnaire. We explained the questions to the patients in their local language to those who were nonconversant in English. The OSDI questionnaire was used to quantify the dry eye symptoms. Subjects were asked questions regarding the dry eye symptoms they had experienced during a 1-week recall period; the OSDI questions were drawn from 3 different subscales: ocular symptoms, vision-related functions, and environmental triggers. Each answer was scored on a 4-point scale from zero (indicating no problems) to four (indicating a significant problem). Responses to all of the questions were combined to generate a composite OSDI score that ranged from 0 to 100 , with higher OSDI scores indicating more severe symptoms [14].

The diagnosis of DED was based on the 2017 International Dry Eye Workshop II (DEWS) and Asia Dry Eye Society (ADES) criteria which rely on the positive symptomatology (Ocular Surface Disease In$\operatorname{dex}>13$ ) and TBUT or Schirmer's < 10 seconds [14].

The patients were allowed to exit the study following severe DED (OSDI $\geq 33$ and TBUT was $<3$ seconds), which was not controlled on the study treatment by day $7^{\text {th }}$. They were then managed by warm compresses, lubricants, artificial tear substitutes, antibiotic steroid combination with an increased frequency, and intense pulse light therapy. The treatment of those patients was then not recorded in the study.

An interim analysis was done on day $7^{\text {th }}$. The primary investigator and the mentor ensured that the study was conducted ethically. There was no separate data safety and monitoring committee to monitor the trial.

The primary outcome measures were changes in BCVA, Schirmer test, TBUT, and OSDI. The secondary outcome measures were changes in MGCD after surgery in the follow-up of 1 month and adverse effects.

\section{Statistical analysis}

Categorical variables were presented in number and percentage (\%), and continuous variables were presented as mean \pm SD and median. Normality of data was tested by Kolmogorov-Smirnov test. If the normality was rejected, then a non-parametric test was used.

Statistical tests were applied as follows:

1. Quantitative variables were compared using the Kruskal Wallis test (for BCVA, Schirmer's test, TBUT, OSDI, and inferior MGCD) and ANOVA(for age) between the three groups.

2. Gender was compared using the $\chi^{2}$ test.

A p-value of $<0.05$ was considered statistically significant.

The data was entered in MS EXCEL spreadsheet, and analysis was done using Statistical Package for Social Sciences (SPSS) version 21.0.

\section{RESULTS}

A total of 278 patients were found eligible, among which 270 patients were enrolled, with 90 patients in each group. Though the surgery and baseline assessment was done in all patients, $12 \mathrm{pa}$ tients were lost to follow-up. The CONSORT flow diagram of the study is shown in Figure 1.

The study patients' mean age was $>70$ years in all three groups $(p=0.828)$. The gender distribution showed equivalent $\mathrm{M}: \mathrm{F}$ in the three groups $(p=0.259)$. The mean duration of surgery was 31.7 minutes in Group A, 32.3 minutes in Group $\mathrm{B}$, and 32.5 minutes in Group $\mathrm{C}(\mathrm{p}=0.09)$. The distribution of smokers (24.44\% in Group A, 30\% in Group B, and 31.11\% in Group C, p = 0.569) and diabetics (40\% in Group A, 45.56\% in Group $B$, and $43.33 \%$ in Group C, $p=0.75$ ) were comparable among the study groups. The baseline demographic and clinical characteristics have been shown in Table 1.

Post-cataract surgery, there was an improvement in the BCVA on day $7^{\text {th }}$ and day $30^{\text {th }}$ in all three groups. In comparison, this improvement was not significantly different (Tab. 2, Fig. 2). 


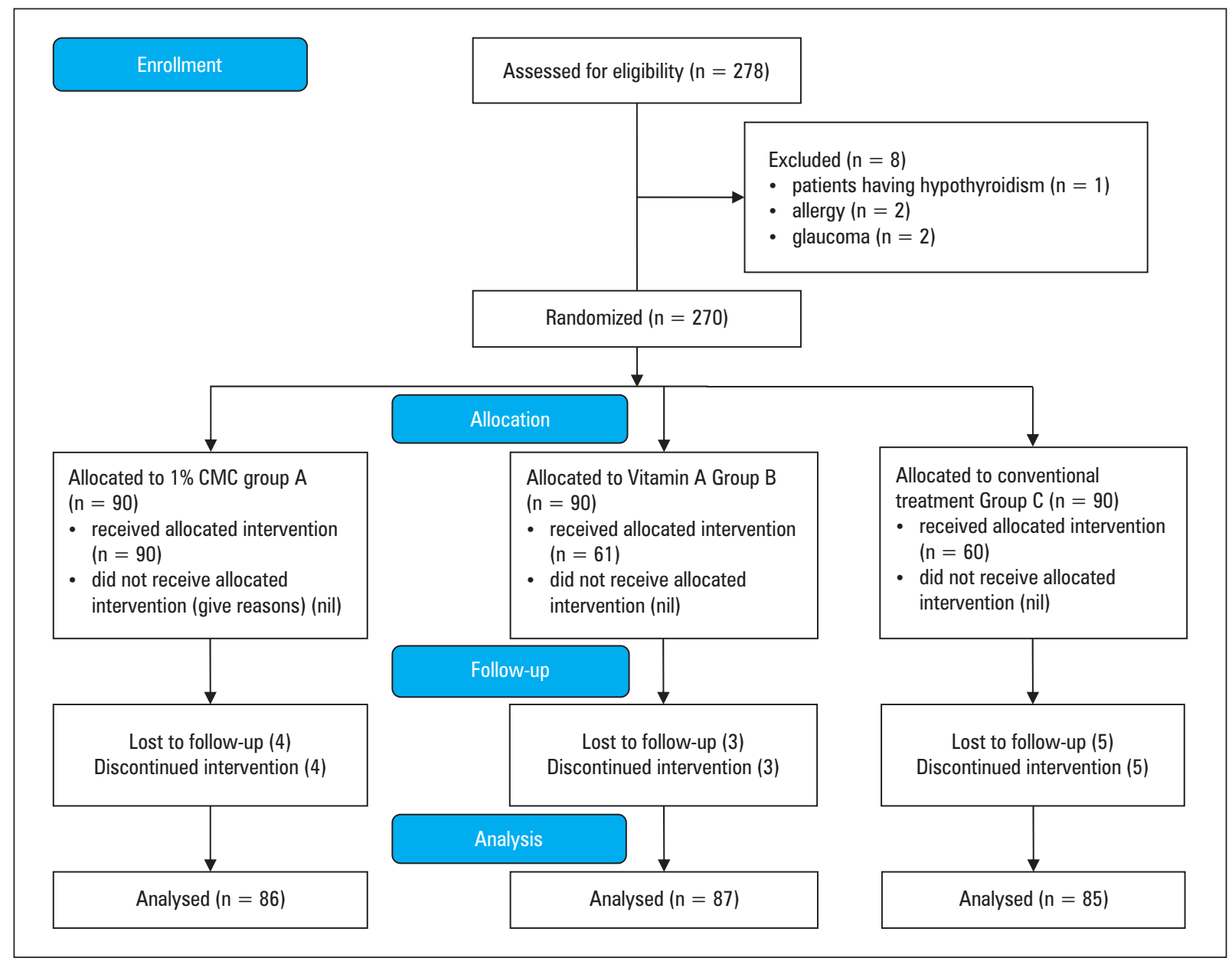

FIGURE 1. CONSORT 2010 Flow Diagram

\begin{tabular}{|c|c|c|c|c|}
\hline Baseline characteristic & $\begin{array}{l}\text { Group A } \\
(\mathrm{n}=90)\end{array}$ & $\begin{array}{l}\text { Group B } \\
(\mathrm{n}=90)\end{array}$ & $\begin{array}{l}\text { Group C } \\
(\mathrm{n}=90)\end{array}$ & p-value \\
\hline Age years (mean $\pm S D$ ) & $70.12 \pm 5.51$ & $70.51 \pm 6.43$ & $70.52 \pm 6.2$ & $0.828^{*}$ \\
\hline \multicolumn{5}{|l|}{ Gender } \\
\hline Female, n (\%) & $49(54.44 \%)$ & $50(55.56 \%)$ & $40(44.44 \%)$ & \multirow{2}{*}{$0.259^{s}$} \\
\hline Male, n (\%) & $41(45.56 \%)$ & $40(44.44 \%)$ & $50(55.56 \%)$ & \\
\hline $\begin{array}{l}\text { Duration [min] } \\
\text { (Mean } \pm \text { SD) }\end{array}$ & $31.7 \pm 2.56$ & $32.3 \pm 3.54$ & $32.5 \pm 3.45$ & $0.09 *$ \\
\hline Diabetes & $36(40 \%)$ & $41(45.56 \%)$ & $39(43.33 \%)$ & $0.750^{* *}$ \\
\hline Smokers & $22(24.44 \%)$ & 27 (30\%) & $28(31.11 \%)$ & $0.569 * *$ \\
\hline
\end{tabular}

${ }^{*}$ ANOVA; ${ }^{*} \chi^{2}$ test

No significant differences were observed in the Schirmer test (mean $\pm \mathrm{SD}$ ) between the three groups at the baseline $(\mathrm{p}=0.969)$. The mean values were above the cutoff of $10 \mathrm{~mm}$ at baseline. However, post-surgery, there was a significant fall in the values on day $7^{\text {th }}$ such that the mean values in all the three groups were less than $10 \mathrm{~mm}$ and were positive. On day $30^{\text {th }}$ after cataract surgery, there was a significant improvement in the Schirmer test in both the intervention groups as compared to 


\begin{tabular}{|c|c|c|c|c|c|c|c|}
\hline \multirow{2}{*}{$\begin{array}{l}\text { BCVA } \\
\text { Median (IOR) }\end{array}$} & \multicolumn{2}{|c|}{ Group A } & \multicolumn{2}{|c|}{ Group B } & \multicolumn{2}{|c|}{ Group C } & \multirow{2}{*}{ p-value } \\
\hline & $\mathbf{n}$ & Score & $\mathbf{n}$ & Score & $\mathbf{n}$ & Score & \\
\hline Baseline & 90 & $\begin{array}{c}1 \\
(0.600-1.080)\end{array}$ & 90 & $\begin{array}{c}1 \\
(0.600-1.080)\end{array}$ & 90 & $\begin{array}{c}0.78 \\
(0.570-1.170)\end{array}$ & $0.914^{*}$ \\
\hline On day $7^{\text {th }}$ & 86 & $\begin{array}{c}0.48 \\
(0.300-0.480)\end{array}$ & 87 & $\begin{array}{c}0.48 \\
(0.300-0.480)\end{array}$ & 85 & $\begin{array}{c}0.3 \\
(0.300-0.480)\end{array}$ & $0.604^{*}$ \\
\hline On day $30^{\text {th }}$ & 86 & $\begin{array}{c}0.3 \\
(0.180-0.300)\end{array}$ & 87 & $\begin{array}{c}0.3 \\
(0.180-0.300)\end{array}$ & 85 & $\begin{array}{c}0.18 \\
(0.180-0.300)\end{array}$ & $0.548^{*}$ \\
\hline $\begin{array}{l}\text { Percentage improvement from baseline } \\
\text { on day } 7^{\text {th }}\end{array}$ & 86 & $52(50-61.538)$ & 87 & $\begin{array}{c}55.56 \\
(50-61.538)\end{array}$ & 85 & $\begin{array}{c}55.56 \\
(50-61.779)\end{array}$ & $0.792^{*}$ \\
\hline $\begin{array}{l}\text { Percentage improvement from baseline } \\
\text { on day } 30^{\text {th }}\end{array}$ & 86 & $70(70-76.923)$ & 87 & $\begin{array}{c}72.22 \\
(70-76.923)\end{array}$ & 85 & $\begin{array}{c}72.22 \\
(70-76.923)\end{array}$ & $0.748^{*}$ \\
\hline
\end{tabular}

*Kruskal Wallis test

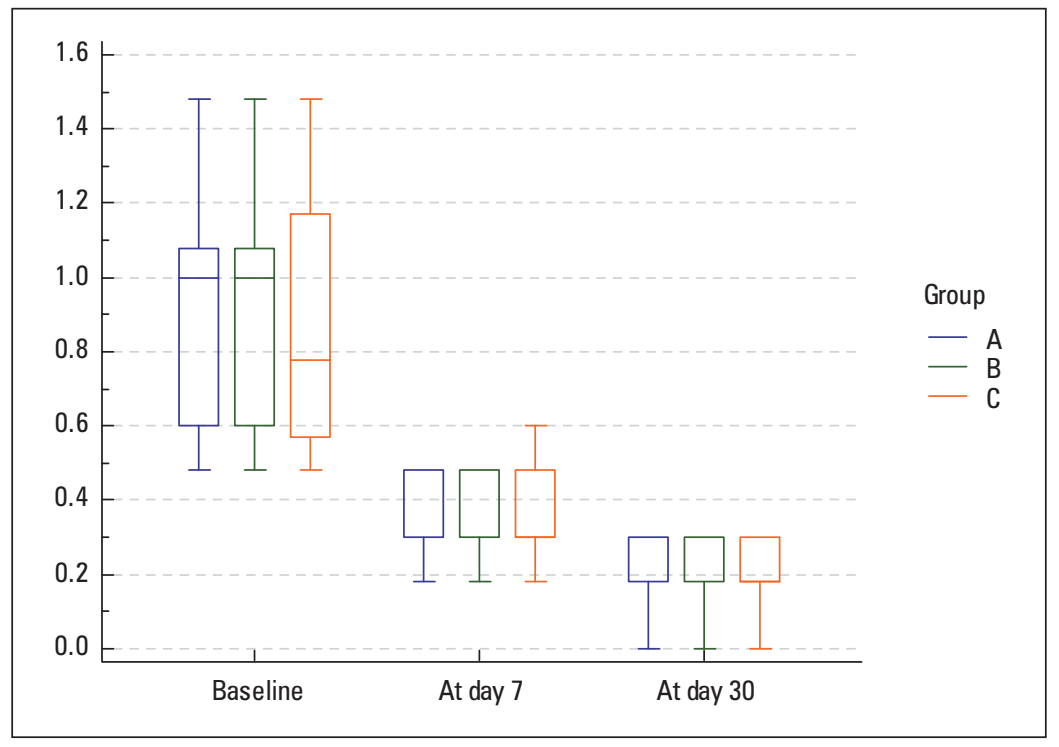

FIGURE 2. Comparison of best-corrected visual acuity (BCVA)

the control, with significantly more improvement in Group B (30\%) as compared to Group A (9\%), $\mathrm{p}<0.0001$. Among the controls, even on day $30^{\text {th }}$, the values were less than the baseline, with mean values less than $10 \mathrm{~mm}$. The final Schirmer test (mean $\pm \mathrm{SD}$ ) on day $30^{\text {th }}$ showed significantly better results in Group B than in Group A, and controls $(12.3 \pm 2.23$ vs. $11.2 \pm 3.11$ vs. $9.25 \pm 2.51$; $\mathrm{p}<$.0001) (Tab. 3, Fig. 3)

No significant differences were observed in the TBUT (mean \pm SD) between the three groups at the baseline $(p=0.42)$. The mean values were above the cutoff of $10 \mathrm{sec}$ at baseline. However, there was a significant fall in the values on day $7^{\text {th }}$ in the three groups post-surgery, but the fall was more in the control group than Group A than Group B. On day $30^{\text {th }}$ after cataract surgery, there was a significant improvement in the Schirmer test in both the intervention groups as compared to the control, with significantly more improvement in Group B (28\%) as compared to Group A (9\%), $\mathrm{p}<0.0001$. Among the controls, even on day $30^{\text {th }}$, the values were less than the baseline, with mean values less than $10 \mathrm{sec}$. The final TBUT (mean \pm SD) on day $30^{\text {th }}$ was significantly longer in Group B than Group A and controls $(12.86 \pm 2.56$ vs. $11.16 \pm 2.67$ vs. $9.67 \pm 2.86$; $\mathrm{p}<$. 0001). (Tab. 4, Fig. 4)

No significant differences were observed in the OSDI (mean \pm SD) between the three groups at the baseline $(p=0.953)$. The mean values were above the cutoff score of 35 at baseline. However, post-surgery, there was a significant fall in 


\begin{tabular}{|c|c|c|c|c|c|c|c|}
\hline \multirow{2}{*}{$\begin{array}{l}\text { Schirmer's test [mm] } \\
\text { Median (IQR) }\end{array}$} & \multicolumn{2}{|r|}{ Group A } & \multicolumn{2}{|r|}{ Group B } & \multicolumn{2}{|r|}{ Group C } & \multirow{2}{*}{ p-value } \\
\hline & $\mathbf{n}$ & Score & $\mathbf{n}$ & Score & $\mathrm{n}$ & Score & \\
\hline Baseline & 90 & $10(8-13)$ & 90 & $11(8-14)$ & 90 & $11(9-12)$ & $0.969 *$ \\
\hline On day $7^{\text {th }}$ & 86 & $8(6-10)$ & 87 & $10(7-12)$ & 85 & $7(5.750-9)$ & $<.0001^{*}$ \\
\hline On day $30^{\text {th }}$ & 86 & $11(9-14)$ & 87 & $13(11-14)$ & 85 & $9(8-11)$ & $<.0001^{*}$ \\
\hline $\begin{array}{l}\text { Percentage improvement } \\
\text { from baseline on day } 7^{\text {th }}\end{array}$ & 86 & $\begin{array}{c}-20 \\
(-25.000-15.385)\end{array}$ & 87 & $\begin{array}{c}-9.09 \\
(-14.048-0.000)\end{array}$ & 85 & $\begin{array}{c}-28.57 \\
(-33.333-25.000)\end{array}$ & $<.0001^{*}$ \\
\hline $\begin{array}{l}\text { Percentage improvement } \\
\text { from baseline on day } 30^{\text {th }}\end{array}$ & 86 & $\begin{array}{c}8.39 \\
(0.000-14.286)\end{array}$ & 87 & $\begin{array}{c}11.11 \\
(6.786-42.857)\end{array}$ & 85 & $\begin{array}{c}-8.33 \\
(-15.705-0.000)\end{array}$ & $<.0001^{*}$ \\
\hline
\end{tabular}

*Kruskal Wallis test

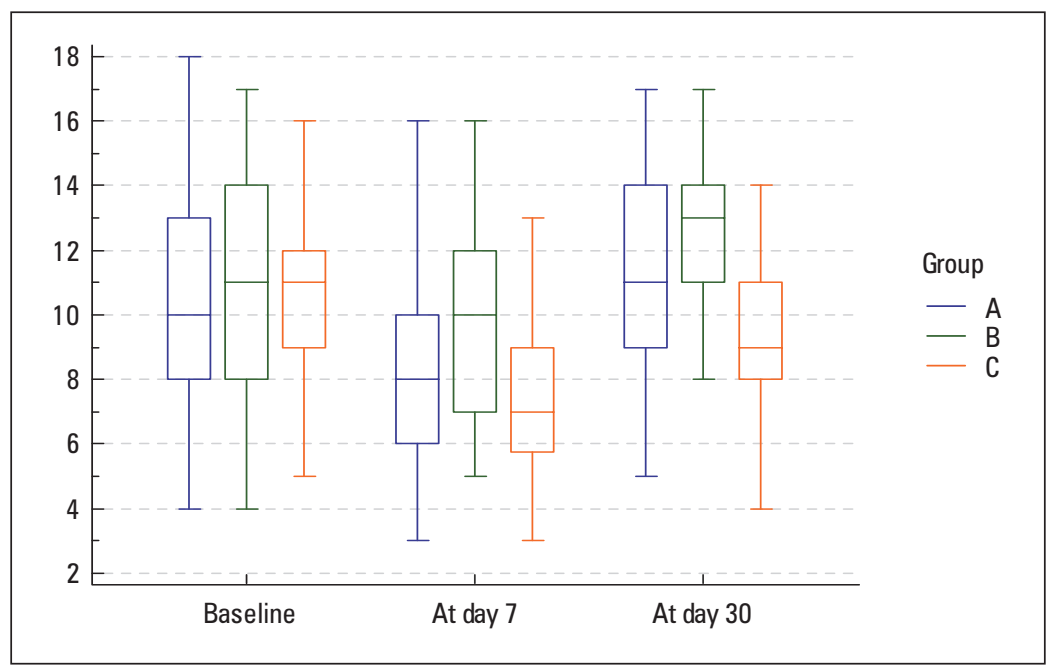

FIGURE 3. Comparison of Schirmer's test

\begin{tabular}{|c|c|c|c|c|c|c|c|}
\hline \multirow{2}{*}{$\begin{array}{l}\text { TBUT [s] } \\
\text { Median (IOR) }\end{array}$} & \multicolumn{2}{|r|}{ Group A } & \multicolumn{2}{|r|}{ Group B } & \multicolumn{2}{|r|}{ Group C } & \multirow{2}{*}{ p-value } \\
\hline & $\mathbf{n}$ & Score & $\mathbf{n}$ & Score & $\mathbf{n}$ & Score & \\
\hline Baseline & 90 & $10(9-12)$ & 90 & $11(7-14)$ & 90 & $11(8-14)$ & $0.42^{*}$ \\
\hline On day $7^{\text {th }}$ & 86 & $8(7-10)$ & 87 & $10(7-13)$ & 85 & $7(6-9)$ & $<.0001^{*}$ \\
\hline On day $30^{\text {th }}$ & 86 & $11(9-13)$ & 87 & $13(11-15)$ & 85 & $9(7-12)$ & $<.0001^{*}$ \\
\hline $\begin{array}{l}\text { Percentage improvement } \\
\text { from baseline on day } 7^{\text {th }}\end{array}$ & 86 & $\begin{array}{c}-18.18 \\
(-23.077-11.111)\end{array}$ & 87 & $\begin{array}{c}-6.67 \\
(-12.500-8.902)\end{array}$ & 85 & $\begin{array}{c}-25(-35.714- \\
-16.071)\end{array}$ & $<.0001^{*}$ \\
\hline $\begin{array}{l}\text { Percentage improvement } \\
\text { from baseline on day } 30^{\text {th }}\end{array}$ & 86 & $9.54(0-16.667)$ & 87 & $16.67(6.667-50)$ & 85 & $\begin{array}{c}-11.11(-18.182 \\
-0)\end{array}$ & $<.0001^{*}$ \\
\hline
\end{tabular}

*Kruskal Wallis test

the values on day $7^{\text {th }}$ and day $30^{\text {th }}$ in the three groups, with the fall being more in Group B than Group A than controls $(\mathrm{p}<0.0001)$. Among the controls, even on day $30^{\text {th }}$, the mean values were above the cutoff score of 35 . The final OSDI scores (mean $\pm \mathrm{SD}$ ) on day $30^{\text {th }}$ were significantly low- er in Group B than in Group A, and controls $(33.42 \pm 1.79$ vs. $34.46 \pm 2.29$ vs. $39.83 \pm 1.72$, $\mathrm{p}<.0001$ ) (Tab. 5, Fig. 5).

No significant differences were observed in the MGCD between the three groups at the baseline $(p=0.859)$. Post-surgery showed a signifi- 


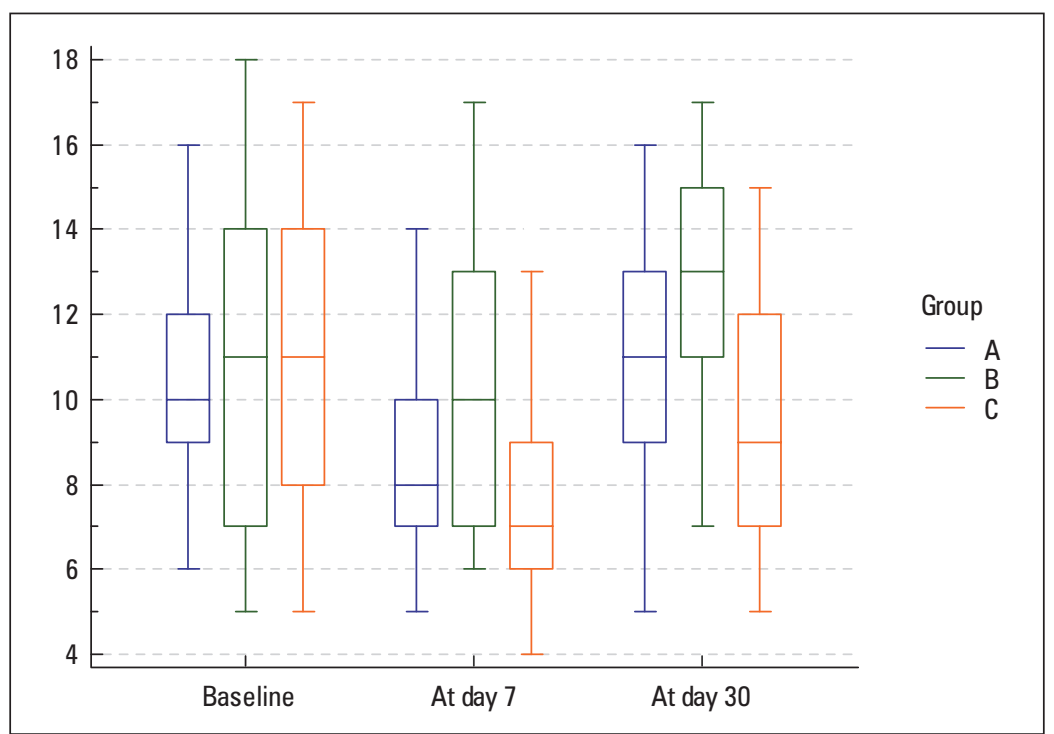

FIGURE 4. Comparison of tear film breakup time (TBUT)

\begin{tabular}{|c|c|c|c|c|c|c|c|}
\hline \multirow{2}{*}{$\begin{array}{l}\text { OSDI } \\
\text { Median (IOR) }\end{array}$} & \multicolumn{2}{|r|}{ Group A } & \multicolumn{2}{|r|}{ Group B } & \multicolumn{2}{|r|}{ Group C } & \multirow{2}{*}{$p$-value } \\
\hline & n & Score & n & Score & n & Score & \\
\hline Baseline & 90 & $\begin{array}{c}45.64 \\
(43.180-47.720)\end{array}$ & 90 & $\begin{array}{c}45.45 \\
(43.180-47.665)\end{array}$ & 90 & $\begin{array}{c}45.45 \\
(43.750-47.500)\end{array}$ & $0.953^{*}$ \\
\hline On day $7^{\text {th }}$ & 86 & $\begin{array}{c}40.9 \\
(38.600-41.660)\end{array}$ & 87 & $\begin{array}{c}37.5 \\
(35.410-39.500)\end{array}$ & 85 & $\begin{array}{c}43.18 \\
(41.600-43.323)\end{array}$ & $<.0001^{*}$ \\
\hline On day $30^{\text {th }}$ & 86 & $\begin{array}{c}34 \\
(31.810-36.300)\end{array}$ & 87 & $\begin{array}{c}33.3 \\
(31.810-34)\end{array}$ & 85 & $\begin{array}{c}39.5 \\
(38.600-40.900)\end{array}$ & $<.0001^{*}$ \\
\hline $\begin{array}{l}\text { Percentage improvement } \\
\text { from baseline on day } 7^{\text {th }}\end{array}$ & 86 & $\begin{array}{c}12.5 \\
(9.269-14.286)\end{array}$ & 87 & $\begin{array}{c}18.39 \\
(16.842-20.853)\end{array}$ & 85 & $\begin{array}{c}5.78 \\
(4.914-8.522)\end{array}$ & $<.0001^{*}$ \\
\hline $\begin{array}{l}\text { Percentage improvement } \\
\text { from baseline on day } 30^{\text {th }}\end{array}$ & 86 & $\begin{array}{c}24.33 \\
(22.770-26.332)\end{array}$ & 87 & $\begin{array}{c}25.81 \\
(23.886-29.189)\end{array}$ & 85 & $\begin{array}{c}12.87 \\
(10.607-13.895)\end{array}$ & $<.0001^{*}$ \\
\hline
\end{tabular}

*Kruskal Wallis test

cant decrease in the MGCD on day $7^{\text {th }}$ in all three groups; the fall was more notable in controls than in Group A and Group B ( $\mathrm{p}<0.0001)$. By the end of day $30^{\text {th }}$, there was an increase in the MGCD (mean \pm SD) in all the three groups, with the values being significantly higher in Group B than in Group A, and controls $(309.07 \pm 20.26$ vs. $295.18 \pm 22.96$ vs. 277.84 $\pm 20.86, \mathrm{p}<.0001)$ (Tab. 6, Fig. 6).

Adverse effects seen were foreign body sensation, red-eye, and eye swelling. The adverse events were comparable among the three treatment groups, with five patients in Group A, four in Group B, and five in the control group $(p>0.05)$. None of the patients had to exit the study because of severe side effects.

\section{DISCUSSION}

Among the various complications such as foreign body sensation, red-eye, astigmatism, and eye swelling; that cataract surgery endows with itself, major complications affecting the quality of life post-surgery is the occurrence of dry eye disease [21]. The incidence of DED may vary from as low as 9.8 to as high as 96.6 after cataract surgery, depending upon the use of different cutoff test measures such as the Schirmer test, TBUT, and OSDI $[21,22]$. Though DED was considered a diagnosis of exclusion, the recent DEWS criteria have been much in use for DED diagnosis, which was also used in the present study [14].

Besides, this incidence of DED is affected by various factors, including surgery (SICS/phacoe- 


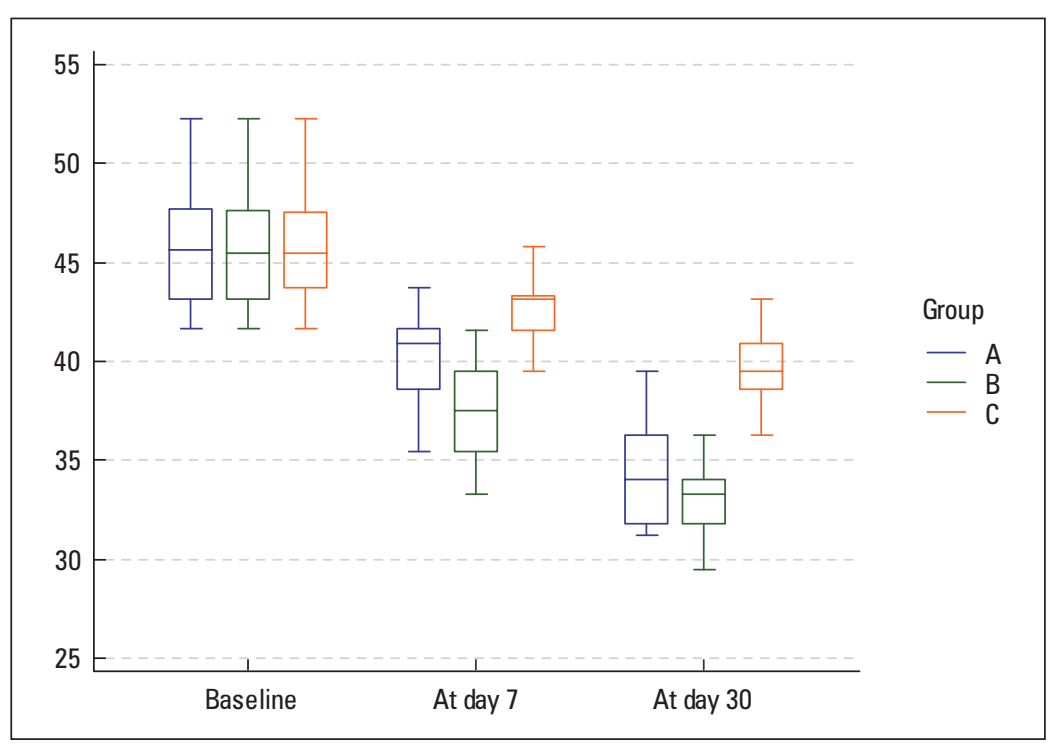

FIGURE 5. Comparison of Ocular Surface Disease Index (OSDI)

\begin{tabular}{|c|c|c|c|c|c|c|c|}
\hline \multirow{2}{*}{$\begin{array}{l}\text { Inferior MGCD } \\
\text { Median (IOR) }\end{array}$} & \multicolumn{2}{|r|}{ Group A } & \multicolumn{2}{|r|}{ Group B } & \multicolumn{2}{|r|}{ Group C } & \multirow{2}{*}{ p-value } \\
\hline & n & Score & n & Score & n & Score & \\
\hline Baseline & 90 & $\begin{array}{c}322.35 \\
(307.400-345.100)\end{array}$ & 90 & $\begin{array}{c}322.5 \\
(293.825-345.800)\end{array}$ & 90 & $\begin{array}{c}322.1 \\
(307.800-338.425)\end{array}$ & $0.777^{*}$ \\
\hline On day $7^{\text {th }}$ & 86 & $\begin{array}{c}274.3 \\
(259.400-291.300)\end{array}$ & 87 & $\begin{array}{c}291.6 \\
(270.600-307.500)\end{array}$ & 85 & $\begin{array}{c}258.9 \\
(242.750-272.475)\end{array}$ & $<.0001^{*}$ \\
\hline On day $30^{\text {th }}$ & 86 & $\begin{array}{c}297.15 \\
(275.800-315.800)\end{array}$ & 87 & $\begin{array}{c}310.5 \\
(292.200-324.175)\end{array}$ & 85 & $\begin{array}{c}275.7 \\
(265.625-297.325)\end{array}$ & $<.0001^{*}$ \\
\hline $\begin{array}{l}\text { Percentage improvement } \\
\text { from baseline on day } 7^{\text {th }}\end{array}$ & 86 & $\begin{array}{c}-15.13(-16.458- \\
-13.763)\end{array}$ & 87 & $\begin{array}{c}-10.9(-12.683- \\
-7.847)\end{array}$ & 85 & $\begin{array}{c}-19.33(-21.326- \\
-17.159)\end{array}$ & $<.0001^{*}$ \\
\hline $\begin{array}{l}\text { Percentage improvement } \\
\text { from baseline on day } 30^{\text {th }}\end{array}$ & 86 & $\begin{array}{c}-9.06(-11.231- \\
-7.547)\end{array}$ & 87 & $\begin{array}{c}-4.82(-7.972-- \\
1.901)\end{array}$ & 85 & $\begin{array}{c}-13.93(-15.583- \\
-12.125)\end{array}$ & $<.0001^{*}$ \\
\hline
\end{tabular}

${ }^{*}$ Kruskal Wallis test

mulsification), an ophthalmic solution used in the surgery, type and use of postoperative medications, coexistent systemic comorbidities, operating microscope exposure time, and time since surgery [21]. Here in the present study, the randomization ensured that the study patients' baseline demographic and clinical characteristics were comparable and any differences in the outcomes were purely due to differential intervention.

We found that both 1\% CMC and retinal palmitate significantly improved dry eye symptoms (OSDI) and tear film layer as assessed by the Schirmer test and TBUT. Interestingly, retinal palmitate was more efficacious compared to $1 \%$ CMC solution and the conventional use of steroids and antibiotics.
The effect of cataract surgery on the teat film-cornea interface and the visual performance has been confirmed in the previous studies [22]. Concurrently, we noted a significant decrease in Schirmer test and TBUT at the first follow-up (day $7^{\text {th }}$ of surgery), indicating that cataract surgery causes dry eye disease. The findings were in line with Garg et al. [21], where one week after surgery, the results of Schirmer's test, TBUT, and OSDI indicated dry eye in $87.5 \%, 69.2 \%$, and $91.7 \%$ patients, respectively. The peak of dry eye symptoms on day $7^{\text {th }}$ post-surgery has been reaffirmed in the study by Kasetsuwan et al. [23]. Among the other studies, Dodia et al. [24] showed that the symptoms start peaking from day 1 of surgery; however, this was not confirmed in our research since we did not evaluate the patients 


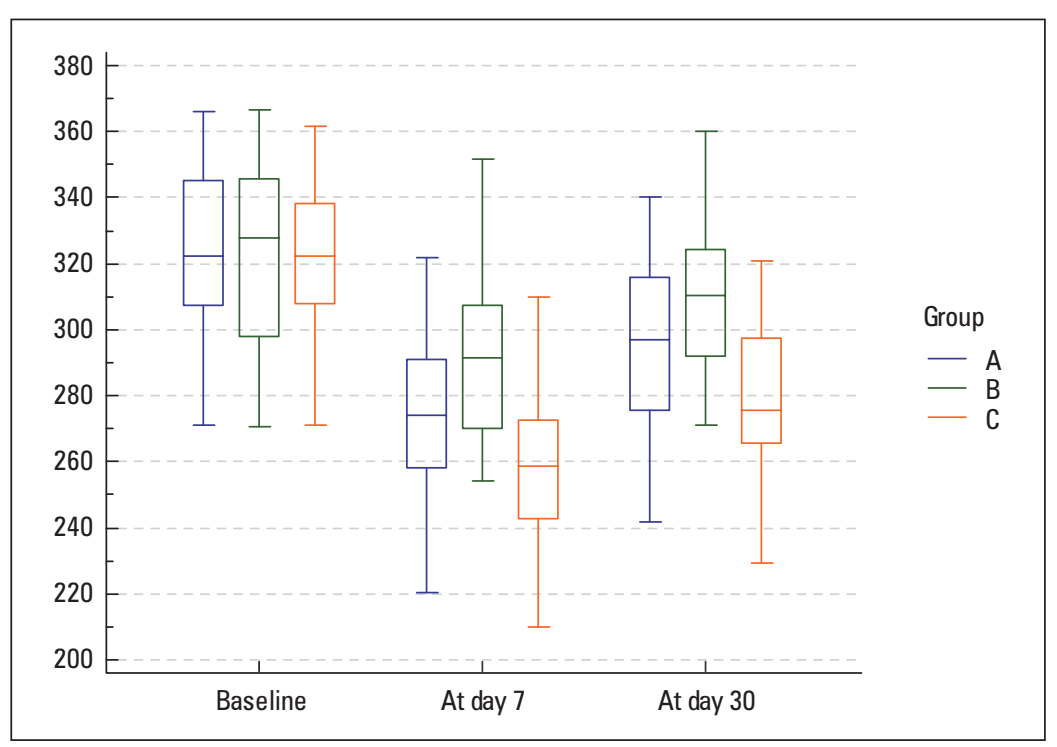

FIGURE 6. Comparison of inferior mean goblet cell density (MGCD)

on day one post-surgery. In another study [25], the data was recorded for up to two years, limiting the current research in terms of a short follow-up. Whereas most of the studies failed to record the tear film parameters in the preoperative phase, our research and Garg et al. [21] study hold strength in this regard. We not only recorded the preoperative tear film characteristics but also found that they were comparable among the three groups.

The analysis showed that OSDI symptoms significantly decreased in all the three groups on day $7^{\text {th }}$ postsurgery continuing up to day $30^{\text {th }}$. The reverse pattern of OSDI symptoms against the Schirmer test and TBUT on day $7^{\text {th }}$ can be ascribed to the fact that such symptoms were more pronounced in the patients due to the concurrent emergence of cataracts with dry eye disease $[22,26]$. Besides, such symptoms that increase the OSDI scores are an inherent feature of cataract itself. After surgery, such symptoms might have shown recovery due to the surgery and resolution of cataract. Mainly due to this reason, OSDI cutoffs or other test values on an individual scenario were not used to categorize DED. Instead, a conglomerate of the tests was used, and their improvement was noted to highlight the effects of the interventions in controlling the DED after cataract surgery.

Additionally, we also found a significant increase in the goblet cells density on day $30^{\text {th }}$ with the use of $1 \% \mathrm{CMC}$ and vitamin $\mathrm{A}$. The decrease in the MGCD immediately after cataract surgery is due to the flushing of the balanced salt solution (BSS) on the ocular surface, a prominent feature of the
DED and is associated with led MUC5AC expression $[27,28]$. The lubricating properties, viscosity, and cornea wetting of the topical solutions help maintain corneal moisture, decrease desiccation of epithelial cells and restore goblet cells much faster. This feature has also been observed using hydroxypropyl methylcellulose (HPMC 2\%) in the study by He et al. [26]. The effectiveness of HPMC $2 \%$ was similar to the present study's $1 \%$ CMC and vitamin A since they show identical properties for tear film protection.

The overall effectiveness of the two interventions (1\% CMC and retinal palmitate) in the study was highlighted by the fact that despite the increase in Schirmer test and TBUT on day $7^{\text {th }}$, the values returned to the baseline and rather improved in comparison to the baseline at day $30^{\text {th }}$. In comparison, a recent study by Garg et al. [21] also showed a significant improvement on day $30^{\text {th }}$ after a fall on day $7^{\text {th }}$, but the values failed to match baseline values even on day $30^{\text {th }}$. These findings show two aspects:

1 - dry eye disease peaks on day $7^{\text {th }}$ and subsequently declines within one month or further;

2 - use of $1 \%$ CMC or topical vitamin A can speed up the reduction in the DED symptoms in the postoperative period.

The effect of 1\% CMC in improving DED after cataract surgery has been shown in a previous study in 2015 [16]. Still, the comparative evaluation of these two modalities has not been done before.

To our knowledge, our study is one of the first studies to compare these two modalities. The better 
efficacy of Vitamin A proposes the fact that vitamin A topically helps in forming the tear film proper and soothing the eyes, thereby reducing the dry eye symptoms similar to artificial tear films.

\section{LIMITATIONS OF THE STUDY}

The exact date and nature of complications could not determine whether they were due to intervention or surgery. The follow-up period of the patients was relatively short. Confounding variables such as smoking was not taken into account. Last, there was no masking or allocation concealment for either the patient or the examiner.

\section{CONCLUSION}

It can be concluded that the use of topical vitamin A on the corneal surface post-cataract surgery reduces the symptoms of dry eyes much faster as compared to $1 \% \mathrm{CMC}$ or conventional treatment. In addition, it helps to restore the goblet cell density and gives a protective effect on the ocular tear film surface. However, all three interventions carried a similar profile of side effects.

\section{Acknowledgement}

None declared.

\section{Conflicts of interest}

None declared.

\section{Funding}

None declared.

\section{REFERENCES}

3. Shanti $Y$, Shehada R, Bakkar MM, et al. Prevalence and associated risk factors of dry eye disease in 16 northern West bank towns in Palestine: a cross-sectional study. BMC Ophthalmol. 2020; 20(1): 26, doi: 10.1186/s12886-019-1290-z, indexed in Pubmed: 31931756.

4. Titiyal JS, Falera RC, Kaur M, et al. Prevalence and risk factors of dry eye disease in North India: Ocular surface disease index-based crosssectional hospital study. Indian J Ophthalmol. 2018; 66(2): 207-211, doi: 10.4103/ijo.IJO 698_17, indexed in Pubmed: 29380759.

5. Gupta N, Prasad I, Jain R, et al. Estimating the prevalence of dry eye among Indian patients attending a tertiary ophthalmology clinic. Ann Trop Med Parasitol. 2010; 104(3): 247-255, doi: 10.1179/13648591 OX12647085215859, indexed in Pubmed: 20507698

6. Donthineni PR, Kammari P, Shanbhag SS, et al. Incidence, demographics, types and risk factors of dry eye disease in India: Electronic medical records driven big data analytics report I. Ocul Surf. 2019; 17(2): 250-256, doi: 10.1016/j.jtos.2019.02.007, indexed in Pubmed: 30802671.

7. Liu Z, Luo L, Zhang Z, et al. [Tear film changes after phacoemulsification]. Zhonghua Yan Ke Za Zhi. 2002; 38(5): 274-277, indexed in Pubmed: 12133372.

8. Vashist $\mathrm{P}$, Talwar $\mathrm{B}$, Gogoi $\mathrm{M}$, et al. Prevalence of cataract in an older population in India: the India study of age-related eye dis- ease. Ophthalmology. 2011; 118(2): 272-278.e1, doi: 10.1016/j. ophtha.2010.05.020, indexed in Pubmed: 20801514.

9. Lamoureux EL, Fenwick E, Pesudovs K, et al. The impact of cataract surgery on quality of life. Curr Opin Ophthalmol. 2011; 22(1): 19-27, doi: 10.1097//CU.0b013e3283414284, indexed in Pubmed: 21088580 .

10. Naderi K, Gormley J, O'Brart D. Cataract surgery and dry eye disease: A review. Eur J Ophthalmol. 2020; 30(5): 840-855, doi: 10.1177/1120672120929958, indexed in Pubmed: 32515220.

11. Sutu C, Fukuoka H, Afshari NA. Mechanisms and management of dry eye in cataract surgery patients. Curr Opin Ophthalmol. 2016; 27(1): 24-30, doi: 10.1097/ICU.0000000000000227, indexed in Pubmed: 26569526.

12. Müller LJ, Vrensen GF, Pels L, et al. Architecture of human corneal nerves. Invest Ophthalmol Vis Sci. 1997; 38(5): 985-994, indexed in Pubmed: 9112994.

13. Sitompul R, Sancoyo GS, Hutauruk JA, et al. Sensitivity change in cornea and tear layer due to incision difference on cataract surgery with either manual small-incision cataract surgery or phacoemulsification. Cornea. 2008; 27 Suppl 1: S13-S18, doi: 10.1097/ IC0.0b013e31817f29d8, indexed in Pubmed: 18813069.

14. Belmonte C, Acosta MC, Gallar J. Neural basis of sensation in intact and injured corneas. Exp Eye Res. 2004; 78(3): 513-525, doi: 10.1016/i.exer.2003.09.023, indexed in Pubmed: 15106930.

15. Chung YW, Oh TH, Chung SK. The effect of topical cyclosporine $0.05 \%$ on dry eye after cataract surgery. Korean $\mathrm{J}$ Ophthalmol. 2013; 27(3): 167-171, doi: 10.3341/kjo.2013.27.3.167, indexed in Pubmed: 23730108.

16. Tsubota K, Yokoi N, Shimazaki J, et al. Asia Dry Eye Society. New Perspectives on Dry Eye Definition and Diagnosis: A Consensus Report by the Asia Dry Eye Society. Ocul Surf. 2017; 15(1): 65-76, doi: 10.1016/j. jtos.2016.09.003, indexed in Pubmed: 27725302.

17. Sánchez MA, Arriola-Villalobos P, Torralbo-Jiménez P, et al. The effect of preservative-free HP-Guar on dry eye after phacoemulsification: a flow cytometric study. Eye (Lond). 2010; 24(8): 1331-1337, doi: 10.1038/ eye.2010.24, indexed in Pubmed: 20300126.

18. Yao Ke, Bao Y, Ye J, et al. Efficacy of 1\% carboxymethylcellulose sodium for treating dry eye after phacoemulsification: results from a multicenter, open-label, randomized, controlled study. BMC Ophthalmol. 2015; 15: 28, doi: 10.1186/s12886-015-0005-3, indexed in Pubmed: 25880685.

19. Garrett $Q$, Simmons $P A, X u S$, et al. Carboxymethylcellulose binds to human corneal epithelial cells and is a modulator of corneal epithelial wound healing. Invest Ophthalmol Vis Sci. 2007; 48(4): 1559-1567, doi: 10.1167/iovs.06-0848, indexed in Pubmed: 17389485.

20. Simmons PA, Vehige JG. Clinical performance of a mid-viscosity artificial tear for dry eye treatment. Cornea. 2007; 26(3): 294-302, doi: 10.1097/ICO.0b013e31802e1e04, indexed in Pubmed: 17413956.

21. Lee JiH, Ahn HS, Kim EK, et al. Efficacy of sodium hyaluronate and carboxymethylcellulose in treating mild to moderate dry eye disease. Cornea. 2011; 30(2): 175-179, doi: 10.1097/IC0.0b013e3181e9adcc, indexed in Pubmed: 21045674.

22. Hatchell DL, Sommer A. Detection of ocular surface abnormalities in experimental vitamin A deficiency. Arch Ophthalmol. 1984; 102(9): 1389-1393, doi: 10.1001/archopht.1984.01040031131040, indexed in Pubmed: 6477255.

23. Garg P, Gupta A, Tandon N, et al. Dry Eye Disease after Cataract Surgery: Study of its Determinants and Risk Factors. Turk J Ophthalmol. 2020; 50(3): 133-142, doi: 10.4274/tjo.galenos.2019.45538, indexed in Pubmed: 32630999.

24. Ishrat S, Nema N, Chandravanshi SCL. Incidence and pattern of dry eye after cataract surgery. Saudi J Ophthalmol. 2019; 33(1): 34-40, doi: 10.1016/j.sjopt.2018.10.009, indexed in Pubmed: 30930661.

25. Kasetsuwan N, Satitpitakul V, Changul T, et al. Incidence and pattern of dry eye after cataract surgery. PLoS One. 2013; 8(11): e78657, doi: 10.1371/journal.pone.0078657, indexed in Pubmed: 24265705.

26. Chudasama R, Bapat S, Dodia K. Dry eye risk factors after phacoemulsification cataract surgery at a secondary care hospital. Int J Health Allied Sci . 2013; 2(4): 242, doi: 10.4103/2278-344x.126711. 
27. Cetinkaya S, Mestan E, Acir NO, et al. The course of dry eye after phacoemulsification surgery. BMC Ophthalmol. 2015; 15: 68, doi: 10.1186/s12886-015-0058-3, indexed in Pubmed: 26122323.

28. He Y, Li J, Zhu J, et al. The improvement of dry eye after cataract surgery by intraoperative using ophthalmic viscosurgical devices on the surface of cornea: The results of a consort-compliant randomized controlled trial. Medicine (Baltimore). 2017; 96(50): e8940, doi: 10.1097/MD.0000000000008940, indexed in Pubmed: 29390284.
29. Li XM, Hu L, Hu J, et al. Investigation of dry eye disease and analysis of the pathogenic factors in patients after cataract surgery. Cornea. 2007; 26(9 Suppl 1): S16-S20, doi: 10.1097/IC0.0b013e31812f67ca, indexed in Pubmed: 17881910.

30. Argüeso P, Balaram M, Spurr-Michaud S, et al. Decreased levels of the goblet cell mucin MUC5AC in tears of patients with Sjögren syndrome. Invest Ophthalmol Vis Sci. 2002; 43(4): 1004-1011, indexed in Pubmed: 11923240. 